\title{
A model for assessing habitat fragmentation caused by new infrastructures in extensive territories - Evaluation of the impact of the Spanish strategic infrastructure and transport plan
}

\author{
S. Mancebo Quintana ，B. Martín Ramos , M.Á. Casermeiro Martínez , I. Otero Pastor \\ Transport Research Center (TRANSyT), Universidad Politécnica de Madrid, Ciudad Universitaria, 28040 Madrid, Spain \\ Department of Soil Science, Faculty of Pharmacy, Universidad Complutense de Madrid, Ciudad Universitaria, 28040 Madrid, Spain
}

Keywords:

Environmental assessment

landscape ecology

Connectivity

Geographic information system

GIS

Spain

\begin{abstract}
A B S T R A C T
The aim of the present work is to design a model for evaluating the impact of planned infrastructures on species survival at the territorial scale by calculating a connectivity index. The method developed involves determining the effective distance of displacement between patches of the same habitat, simplifying earlier models so that there is no dependence on specific variables for each species. A case study is presented in which the model was used to assess the impact of the forthcoming roads and railways included in the Spanish Strategic Infrastructure and Transport Plan (PEIT, in its Spanish initials).

This study took into account the habitats of peninsular Spain. which occupies an area of some $500.000 \mathrm{~km}^{2}$. In this territory, the areas deemed to provide natural habitats are defined by Directive 92 f 43/EEC. The impact of new infrastructures on connectivity was assessed by comparing two scenarios. with and without the plan, for the major new road and railway networks. The calculation of the connectivity index (CI) requires the use of a raster methodology based on the Arc/Info geographical information system (GIS). The actual calculation was performed using a program written in Arc/Info Macro Language (AML); this program is available in FragtULs (Mancebo Quintana, 2007), a set of tools for calculating indicators of fragmentation caused by transport infrastructure (http:/topografia.montes. upm.es/fragtuls.html).

The indicator of connectivity proposed allows the estimation of the connectivity between all the patches of a territory, with no artificial (non-ecologically based) boundaries imposed. The model proposed appears to be a useful tool for the analysis of fragmentation caused by plans for large territories.
\end{abstract}

\section{Introduction and objectives}

Fragmentation is a process in which a habitat becomes divided into units of smaller size known as patches; it is also characterised by a reduction in the total area the habitat occupies. The resulting patches may be very similar but may also have characteristics of their own, a consequence of their size, shape and boundaries etc. (Forman, 1995). In most cases, the fragmentation of natural ecosystems into patches is a product of human activity; man modifies the use of the land, transforming parts of natural habitats into artificial environments. One of the main causes of habitat fragmentation is the construction of linear infrastructures (Geneletti, 2004). These not only reduce the area of the habitats they cross, but may also affect the structure and functioning of the territory as a whole by acting as a barrier to the movement and migration of animal and plant species (Forman, 1995).

New transport infiastructures, such as major and minor roads (van Langevelde et al., 2009), are recognised as one of the main threats to the conservation of biodiversity (Geneletti, 2006; Mata et al., 2008). They affect the functioning of ecosystems, and alter the biotic and abiotic conditions of the patches that compose them (Saunders et al., 1991). Their main effects are threefold: they increase the isolation of habitat patches, reduce their size, and increase their exposure to exogenous perturbations (Geneletti, 2004). Transport infrastructures behave as barriers to (or filters of) the movement of energy and materials (Forman and Alexander, 1998). Among the abiotic factors affected are the hydrological settings, the incidence of solar radiation, humidity, wind and soil conditions (Collinge, 1996; Forman, 1995). These changes in the macroscopic properties of the ecosystem affect the structure 
composition and population dynamic. The long-term survival of some species may be threatened due to the degradation of the area's biodiversity, a reduction in its integrity and stability, and a diminished capacity of the area to recover from the assault of disturbances (Baskent, 1999; Saunders et al., 1991).

The loss of area caused by habitat fragmentation has important ecological implications - the relationship between area and species richness is a basic tenet of ecology (May, 1975). The direct and indirect impacts of development and the construction of transport infrastructures reduce the areas of the natural environments they cross, and the resulting patches may be too small for the survival of some species. In other words, the modification of a territory may reduce the area of its habitat(s) to below the survival threshold (Fahrig, 2002; Opdam et al., 2001).

Dunning et al. (1992) interpret the set of habitat patches as a landscape; they define this as an area composed of a mosaic of patches that sustain associated biological systems. The configuration and nature of the landscape that surrounds these patches determines whether a region's biodiversity can be guaranteed (Lindenmayer and Franklin, 2002). The capacity of an ecosystem to preserve its integrity and biodiversity increases in large habitats that are well connected and which are far from the influence of external disturbances (Fahrig and Merriam, 1985). Habitat fragmentation can be understood as a landscape's loss of connectivity, the mechanism leading to this, and the resulting changes in ecological processes (Serrano et al., 2002). Connectivity is a vital element of landscape structure (Taylor et al., 1993) and is defined as the degree to which the landscape facilitates or impedes the movement of organisms between patches (Taylor et al., 1993; Tischendorf and Fahrig, 2000b). This definition not only views connectivity from the perspective of the theory of island biogeography (MacArthur and Wilson, 1967), i.e., as the physical continuity of a determined type of habitat (structural connectivity), it also takes into account factors related to each organism's mobility and its perception of the landscape (functional connectivity) (Adriaensen et al., 2003). Any biusque change in the connectivity of an area's patches, such as that caused by a new linear infrastructure, can interfere in the ecological flux of populations (metapopulation dynamics), perhaps even leading to their extinction (Forman and Alexander, 1998; McGarigal and Marks, 1995).

The degree of habitat fragmentation is often measured by indicators that quantify the composition or spatial configuration of the landscape (Gustafson and Gardner, 1996). These indicators have been developed alongside advances in landscape ecology as a response to the growing need to understand how species and ecosystems have evolved in the face of human activity. The literature contains many indices for characterising habitat fragmentation (McGarigal and Marks, 1995; Riitters et al., 1995; Rutledge, 2003; Quine and Watts, 2009; Jaeger et al., 2008) and many authors have proposed different connectivity models and indicators (e.g., Tischendorf and Fahrig, 2000a; Moilanen and Hanski, 2001; Pascual-Hortal and Saura, 2006; Saura and Pascual-Hortal, 2007).

The measurement of connectivity needs to take into account both the structural and functional aspects that define this concept. However, many models for predicting metapopulation dynamics regard the structure of the landscape between habitats to be of little interest; some even ignore it completely (Stevens et al., 2004). The quantification of functional connectivity should include variables relating to the structural characteristics of the matrix making up the landscape that surrounds the patches, as well as aspects associated with the behaviour of the species that must cross this matrix in order to move between patches (Adriaensen et al., 2003). Some elements of the landscape matrix offer more resistance to movement than others, and can condition the dispersion patterns of organisms. Many studies have used effective distance models that take into account the opposition to the movement of organisms between patches. In these models, each element in the matrix is assigned a friction value that quantifies this opposition (Adriaensen et al., 2003; Bunn et al., 2000; Drielsma et al., 2006; Marulli and Mallarach, 2005; Nikolakaki, 2004).

Indicators need to be validated, and Saura and Pascual-Hortal (2007) have therefore proposed four points that must be established in order to perform this validation: these indicators must not "(i) indicate that landscape connectivity increases with increasing habitat fragmentation; (ii) predict zero connectivity in any landscape containing just one habitat patch, even if that habitat patch covers the whole landscape; (iii) be insensitive to the loss of (possibly large) isolated patches; (iv) be unable to detect as more important those key stepping-stone patches that, when lost, disconnect the remaining habitat in two or more isolated sets of patches".

The inclusion of the effects of fragmentation on assessment methodologies has, however, been scant and uneven. One of the most common defects in the assessment of the impact of linear infrastructures on habitats is that insufficient importance is given to biodiversity. In addition, in many investigations the study area is not defined with any ecological basis, and the ecological value of the whole area to be crossed is not taken into account; rather, assessment is restricted to protected areas or to a band of variable width on either side of the linear infrastructure (Geneletti, 2006).

The consequences of poor planning for transport infrastiuctures generally become evident in the long term, when management becomes very difficult and the processes degrading biodiversity have become irreversible. Methodologies that assess the impact of habitat fragmentation are therefore required and should be used during decision-making procedures (European Commission, 2003). The Strategic Environmental Assessment Directive (Official Journal of European Communities, 2001) includes biodiversity as one of the environmental factors to be assessed, though there are few tools for doing so (Gontier et al., 2006). One reason for this is that the extensive tertitories usually involved in planning processes make ecological models for single species difficult to use. Since studying each species separately is unviable, simplified models are required.

The experiments reviewed within the framework of the present study involved specific population groups. Hanski (1994) proposed a model for predicting the survival/extinction of metapopulations (which he used with butterflies) which takes into account the distance between patches (among other variables). Drielsma et al. (2006) used Hanski's equation but substituted Euclidean distances for effective distances (Bunn et al., 2000). Nikolakaki (2004) analysed connectivity with the aim of finding new zones for a particular species of bird, performing studies on the specific resistance of the matrix to movement by this species. New infrastructures involve activities over large areas of territory and can increase the resistance to movement of many of the species present. However, the number of species involved is usually so large that the above methods cannot predict the impact of such activities. Marulli and Mallarach (2005) solved the problem of how to construct resistance matrices by recognizing ecologically equivalent units, which these authors defined on the basis of land cover. The resistance presented by each unit to the movement of each individual species from other units is assumed to be the same. This method involves determining the resistance of all possible pairs of established units, a task undertaken by a panel of experts.

Adriaensen et al. (2003) studied the effective distance between patches as a measure of the resistance to the movement of species. This makes it possible to assess the effects of infrastiucture on the connectivity between patches. The number of patches potentially affected in a large territory is, however, huge, and hinders the use of this approach. 
The aim of the present work was to design a new model for evaluating the impact of planned infrastructures on species survival at the territorial scale by calculating a connectivity index. The proposed methodology is designed to solve two problems encountered by previous authors: 1) the availability of valid ecological models, and 2) how to implement these in extensive areas.

The method developed involves determining the effective distance of displacement between patches of the same habitat, simplifying earlier models so that there is no dependence on specific variables for each species. This methodology was tested in a case study in which measurements were made of the loss of connectivity between habitat patches caused by the roads and railways included in the Spanish Strategic Infrastructure and Transport Plan (PEIT, in its Spanish initials).

\section{Methods and materials}

\subsection{Method description}

\subsubsection{Connectivity index}

The method involves the calculation of a new connectivity index, which is conceptually based on Hanski's metapopulation model (1994); the index shows the following equation:

$C I_{i}=\frac{\sum_{j=1}^{n} \frac{A_{j}}{d e_{i, j}}}{2 \pi d e_{\max }}$

where:

- $\mathrm{Cl}_{i}$ is the value of the connectivity index for starting-point cell $i$.

- $A_{j}$ is the area of the destination cell $j$ that belongs to the same class of habitat as starting-point cell $i$.

- de $e_{i, j}$ is the effective distance between starting-point cell $i$ and destination cell $j$.

- And $2 \pi d e_{\max }$ is the maximum possible value of the numerator.

The Hanski metapopulation model, which is specific for every species, is based on the probability of a patch $i$ containing a particular species $\left(p_{i}\right)$ and depends on its local probability of survival ( $p_{\text {local }}$ ) and the rate of immigration $(S)$ :

$p_{i}=f\left(p_{\text {local }}, S\right)$

Hanski introduced the distance between starting point and destination $\left(d_{i j}\right)$ for calculating the number of individuals $(S)$ that can immigrate into a starting-point patch $i$ from a destination patch $j$. This number also depends on the probability of survival of individuals during movement $(\alpha)$ and the number of individuals in the destination patch, given by its area $\left(A_{j}\right)$ :

$S_{i} \propto p_{j} e^{-\alpha d d_{i j}} A_{j}$

where:

- $S_{i}$ index of connectivity of patch $i$

- $p_{j}$ the probability of a patch $j$ containing a particular species

- $d_{i, j}$ is the distance between the starting-point patch $i$ and the destination patch $j$

- $\alpha$ is the probability of an individual surviving migration (0-1).

- And $A_{j}$ is the area of the destination patch $j$

The new Connectivity Index therefore reflects - as information on the structure of the landscape - the area occupied by each habitat, plus its connectivity understood from a functional point of view. This is possible because the effective distance takes into account the resistance offered by the landscape matrix to the movement of species.

Thus, the $\mathrm{CI}$ calculates the connectivity for all the species together, where $d e_{i j}$ is the effective distance due to the resistance inherent in the matrix:

$C_{i j}=\frac{A_{j}}{d e_{i, j}}$

where:

- $C_{i, j}$ is the connectivity between a starting-point cell $i$ and a destination cell $j$.

- $A_{j}=$ Area of destination cell $j$.

- $d e_{i, j}$ is the effective distance between the starting-point cell $i$ and the destination cell $j$.

The present model is based on a raster GIS, so distances are calculated for each cell pair in the same habitat; and $\mathrm{Cl}$ is calculated for each cell considered to be in the habitat. Working with cells instead of patches does not change the model in any way, but allows a more accurate calculation.

The denominator $2 \pi d e_{\max }$ (in eq (1)) is merely a normalization factor; it is the value of the numerator under the best conditions of movement and availability of habitat, i.e., when the effective distance is the same as the Euclidean distance between the starting-point cell and the destination cell when the entire territory has the same habitat. Dividing by this factor always produces a $\mathrm{CI}$ of between 0 and 1 .

The difference between the proposed model and Hanski's model (eq (5), Fig. 1) lies in the fact that the new model does not use $\alpha$ values (which depend on the species). For long-distance movements, the proposed model produces much higher connectivity values than those obtained with the Hanski model performed without iteration. This fact is not a drawback in the model, but a way to avoid performing the time-consuming iterations potentially needed to calculate species survival probability.

The sum of the connectivities, $C_{i, x}$, for all destination cells $j$ at a given distance $x$ is therefore:

$$
C_{i, x}=\sum_{j} \frac{A_{j}}{d e_{i, j}} ; \quad S_{x}=\sum_{j} A_{j} e^{-\alpha d e_{i, j}} \forall j, d e_{i, j}=x
$$

Proposed model Hanski model(without iteration)

Fig. 2 shows that the relative importance of the furthest destinations is very high. This leads to a potential problem: a priori, no

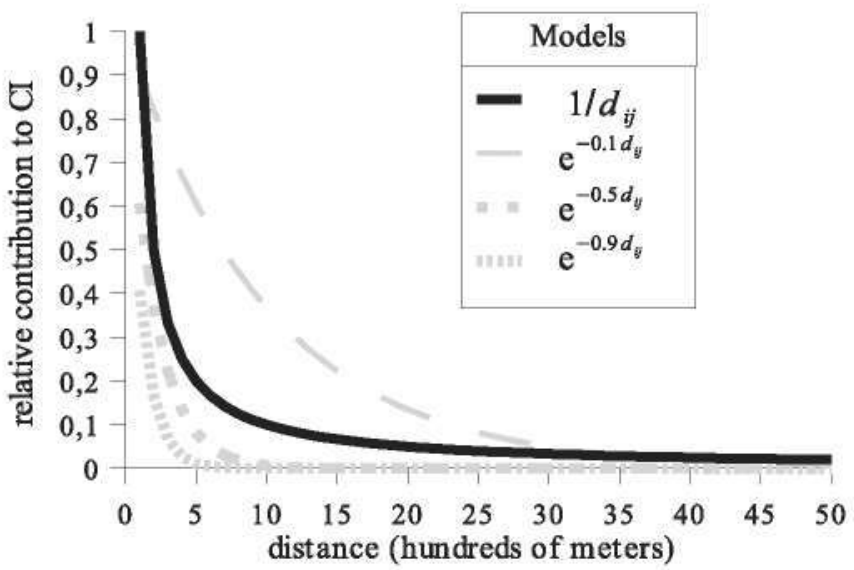

Fig. 1. Connectivity values $\left(C_{i}\right)$ obtained for patch cells at different distances using the proposed and Hanski (without iteration) models. 


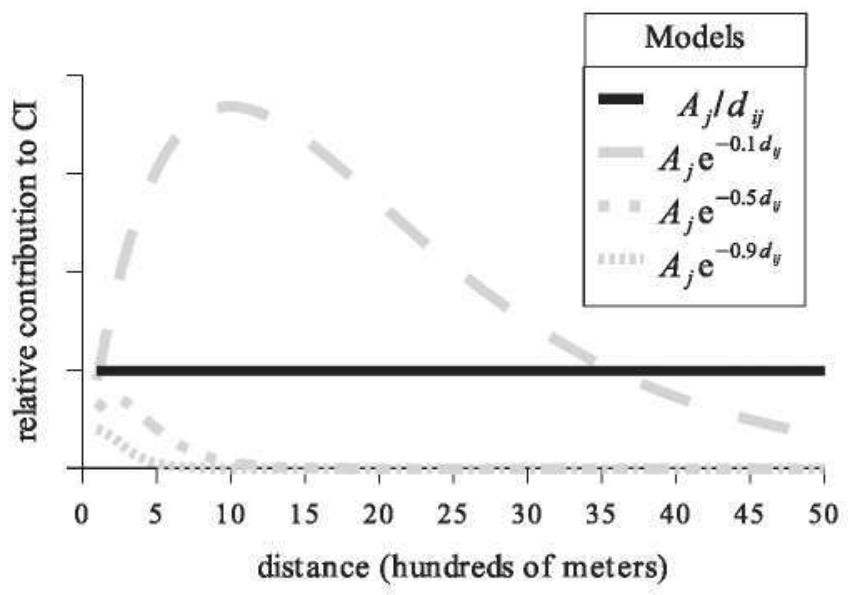

Fig. 2. Relative contribution to $\mathrm{CI}$ of all cells at different distances $\left(C_{i, x}\right)$ using the proposed and Hanski (without iteration) models.

maximum interaction distance between patches can be established - the sum of distant destinations can contribute as much to the $\mathrm{Cl}$ as nearby ones. However, this problem disappears as a consequence of spatial autocorrelation: the nearby patches have a greater probability of belonging to the same type of habitat than the more distant ones. Thus, by performing autocorrelation analysis it is possible to determine the distance beyond which patches do not significantly contribute to $\mathrm{Cl}$, and to use this distance as a threshold for calculations.

The process of simplifying Hanski's model for obtaining the $\mathrm{CI}$ inherently means that the index retains its ecological significance when scenarios are compared. A loss of connectivity reflects a reduction in the probability of the survival of all the species involved.

\subsection{Study area}

\subsubsection{Description of the study case}

This study took into account the habitats of peninsular Spain, which occupies an area of some $500,000 \mathrm{~km}^{2}$. In this territory, the areas deemed to provide natural habitats are defined by Directive 92/43/EEC, which recognises 120 types of habitat (Ministerio de Medio Ambiente, 1995).

The impact of new infrastructures on connectivity was assessed by comparing two scenarios: a 'zero scenario', i.e., the current situation, taking into account the effect on connectivity of already existing linear infrastructures; and a scenario taking into account the effect of all the linear infrastructures planned until 2020 (PEIT scenario).

An analysis was made of the plans for the major new road and railway networks described in the 2005-2020 PEIT (Ministerio de Fomento, 2005). The plans for new high-capacity road infrastructures include increasing the size of the present network by some $15,000 \mathrm{~km}$ by 2020 . By the same date, the high-speed railway network is scheduled to have $10,000 \mathrm{~km}$ of track. The goal fixed by the PEIT is that the railway system should gradually become a central element of intermodal transport services, both for passengers and goods. The aim is for this to contribute towards a more equal territorial development, as recommended by the European Territorial Strategy.

The methodology proposed requires the use of the following:

- A map of habitats (in this case the map of Spanish habitats was used) (Ministerio de Medio Ambiente, 1995).

- Maps showing current and projected infrastructure networks. These maps were provided by Mancebo Quintana, S. and
Ortega Pérez, E. of the Transport Research Centre of the Universidad Politécnica de Madrid.

If the effects of new infrastructures on specific areas are required, further maps will be necessary. In the present study, the following maps were used:

- Maps of Sites of Community Importance (SCI; in this case the $\mathrm{SCI}$ map of Spain was used) (Subdirección General de Conservación de la Biodiversidad, 2005). SCI are natural protected areas which are part of the European Natura 2000 Network (Directive 92/43/EEC).

- Maps of special protection areas for birds (SPA; in this case the SPA map of Spain was used) (Subdirección General de Conservación de la Biodiversidad, 2005). SPAs are also protected under the European Natura 2000 Network (Directive 92/43/ EEC).

- Land cover maps (in this case the Corine Land Cover, 2000 map was used) (EEA, 2000).

In this case study, the starting-point cell size was $100 \mathrm{~m} \times 100 \mathrm{~m}$ ( $1 \mathrm{ha}$ ). These were aggregated to form cells of $1 \mathrm{~km}^{2}$, reducing the number of starting cells from several million to 300,000 , and the processing time from many months or even years to just one week.

\subsection{Application: calculation of the connectivity index}

The Connectivity Index (Cl) proposed is a function of effective distance, i.e., the minimum distance between two points separated by a resistance matrix (Bunn et al., 2000) calculated using the Dijkstra (1959) algorithm. To determine this distance it is necessary to know the starting points and destinations of organisms and the resistance offered by the landscape to movement between these points (a consequence of the elements making up that landscape). The calculation of the connectivity index requires the use of a raster methodology. In this study, the Arc/Info Workstation Geographic Information System (GIS) was used. The actual calculation was performed using a program written in Arc/Info Macro Language (AML); this program is available in FragtUls (Mancebo Quintana, 2007), a set of tools for calculating indicators of fragmentation caused by transport infrastructure (http://topografia.montes.upm. es/fragtuls.html).

\subsubsection{Starting points and destinations}

The map of habitats, divided into different sheets, was transformed into raster format. The cell size chosen in the case study was $100 \mathrm{~m} \times 100 \mathrm{~m}$. Afterwards this was aggregated to $1 \mathrm{~km} \times 1 \mathrm{~km}$ as explained in 2.3.3.

The starting points of the organisms were taken as each of the cells on the habitat map that belonged to patches classified as containing 'habitat' according to Directive 92/43/EEC. To simplify the calculations, the destinations were taken to be those cells on the same map with the same class of habitat as that found in the starting-point cells, i.e., those with the same habitat identification codes as established by the Directive.

\subsubsection{Resistance maps}

Each cell on the resistance map was given a value, a function of the resistance of the territorial matrix to the movement of organisms between patches of the same habitat. This resistance is in fact a function of several factors: the habitat class, land cover, and the type of transport infrastructure present. It should be remembered that an infrastructure plan potentially affects all the species in a territory; thus to calculate accurately the $\mathrm{Cl}$ requires the production of a resistance matrix for each species. As it is unfeasible 
Table 1

Friction coefficients with respect to landscape elements.

\begin{tabular}{ll}
\hline Type & Friction coefficient \\
\hline Habitat of the same class & 1 \\
Habitat of a different class & 2 \\
Artificial area & $2 \sqrt{\pi}$ \\
Motorway or freeway & 16 \\
National road & 8 \\
First-order regional road & 8 \\
Second-order regional road & 4 \\
Local road & 0 \\
Streets and tracks & 0 \\
High-speed railway & 16 \\
Conventional railway & 0 \\
\hline
\end{tabular}

to produce these maps for every species, the model is simplified, assuming that the resistance of each land use and habitat class to all species in a certain habitat is the same (Marulli and Mallarach, 2005). Further simplifications based on the opinions of a panel of experts were also made. The friction coefficients are non-dimensional numbers with a resistance proportional to the minimum value (i.e., 1). The final resistance values are obtained by adding the combined value of land cover and habitat plus the resistance caused by the infrastructures. Table 1 shows the final range of friction coefficients for the different barriers:

- The resistance to movement through another patch of the same class of habitat as that of the starting point was given a value of 1 ; the resistance offered by a patch of a different, non-artificial habitat class was given a value of 2 .

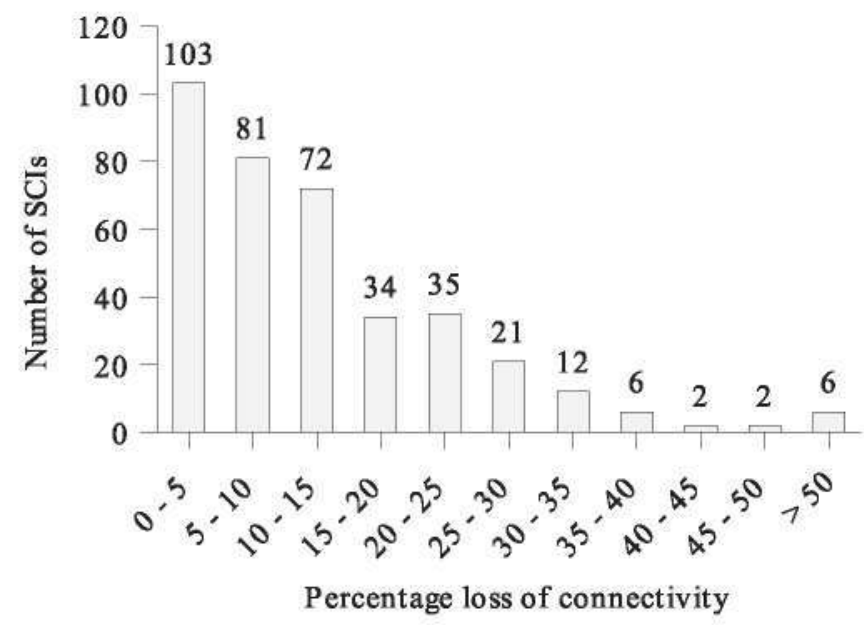

Fig. 4. Distribution of the loss of connectivity suffered by SCIs.

- The difficulty of crossing elements such as urban, commercial and industrial areas (classified in the Corine Land Cover as artificial areas) was understood to be proportional to the distance that would have to be travelled in order to circumnavigate them (assuming such areas to be circular). Thus, the resistance offered by urban elements was defined as $2 \sqrt{\pi}$. This value is obtained via the following reasoning. The area of a cell is the square of the length of its side (resolution), i.e., $\left(A=\operatorname{res}^{2}\right)$; if this cell were a circle of radius $R$, its equivalent area would be $A=\pi R^{2}$. Thus, the radius becomes $R=$ res $/ \sqrt{\pi}$. The distance

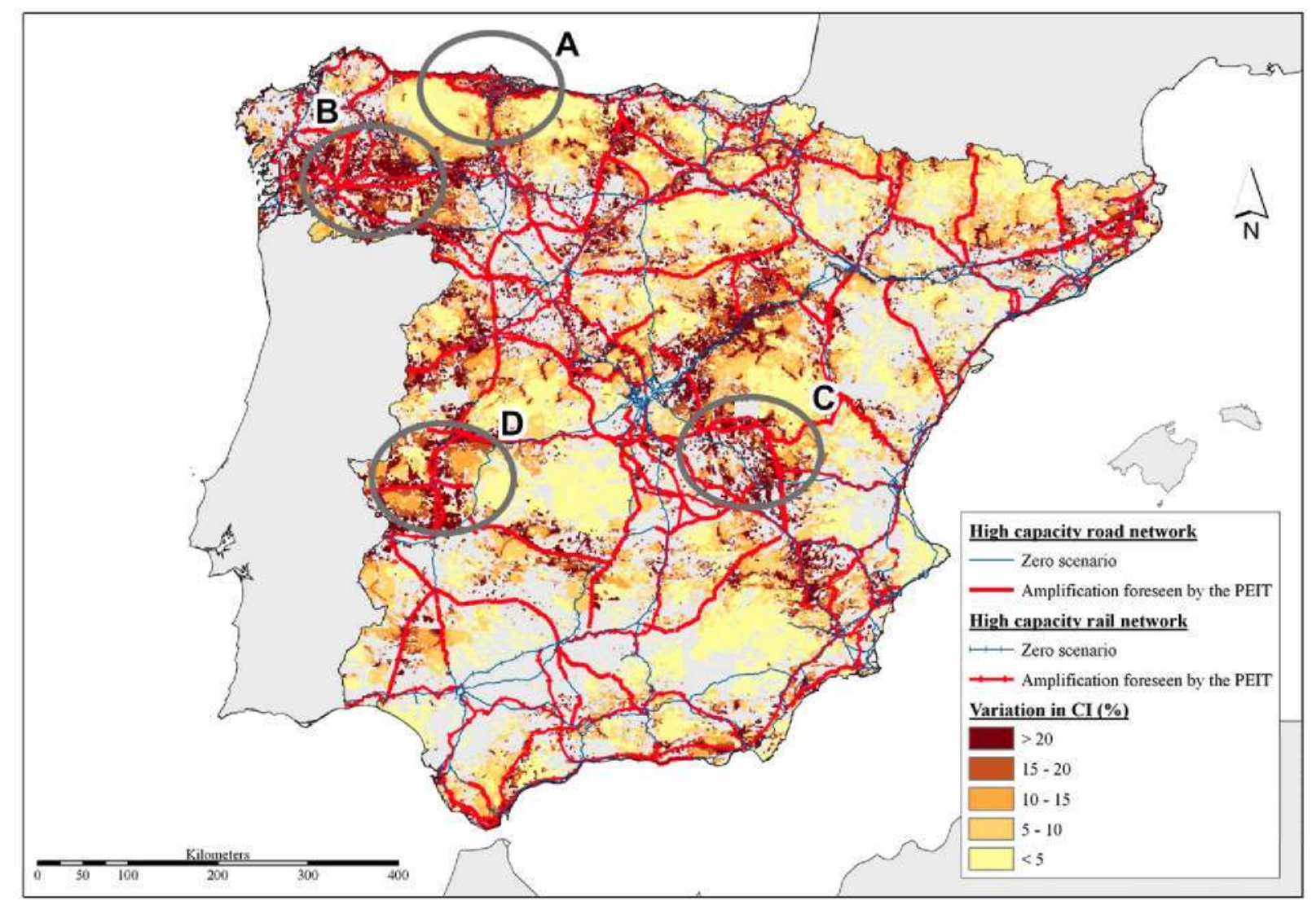

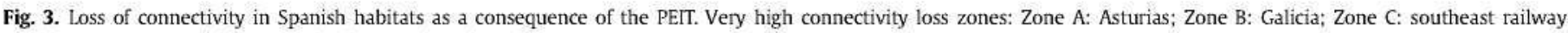
corridors; Zone D: Madrid-Portugal railway and road corridor. 


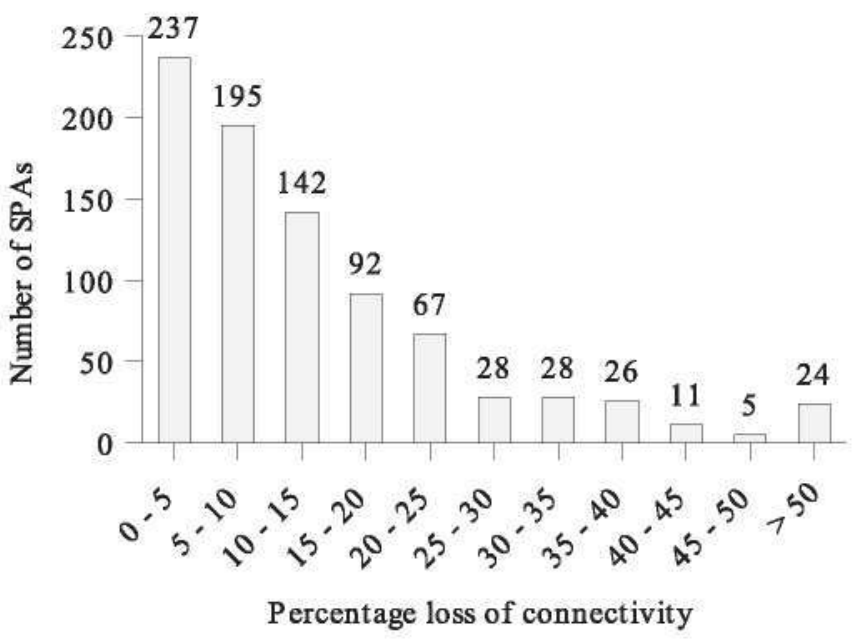

Fig. 5. Distribution of the loss of connectivity suffered by SPAs.

that has to be travelled to circumnavigate the circle is therefore half of its perimeter. If we take into account that the distance to be travelled requires passage through a habitat unlike that of the starting point, the final friction coefficient for this type of cell is supplied by $2 \sqrt{\pi}$.
- In the present study, a minimum friction coefficient of zero was assigned to local roads, streets and tracks, and conventional railways; assuming that these infrastructures do not add resistance to the matrix. The greatest friction coefficient (16) was assigned to high-speed railways, motorways and freeways, infrastructures planned to have fauna-passage points every $3 \mathrm{~km}$. If these types of barrier are considered completely impermeable, the maximum distance that has to be travelled to cross them via a fauna-passage to reach the mirror position on the other side is $3 \mathrm{~km}$. The minimum distance would be $0 \mathrm{~km}$ (except for the width of the infrastructure) when an animal finds itself right next to a fauna-passage. If $100 \mathrm{~m}$ (the width of the cell) is added to the mean of the two previous values, the mean distance to be travelled is $1.6 \mathrm{~km}$, leading to a friction coefficient of 16 ( 16 times the length of a cell).

- A friction coefficient of 8 was assigned to first-order national and regional roads, and 4 to second-order regional roads.

\subsubsection{Optimised aggregation}

A CI should be calculated for each starting-point cell, but this demands a great deal of time. In order to transform a number of cells into 1, a new aggregation methodology was developed. This method, based on statistical techniques, ensures the minimum loss of information. The method is described in the following steps:

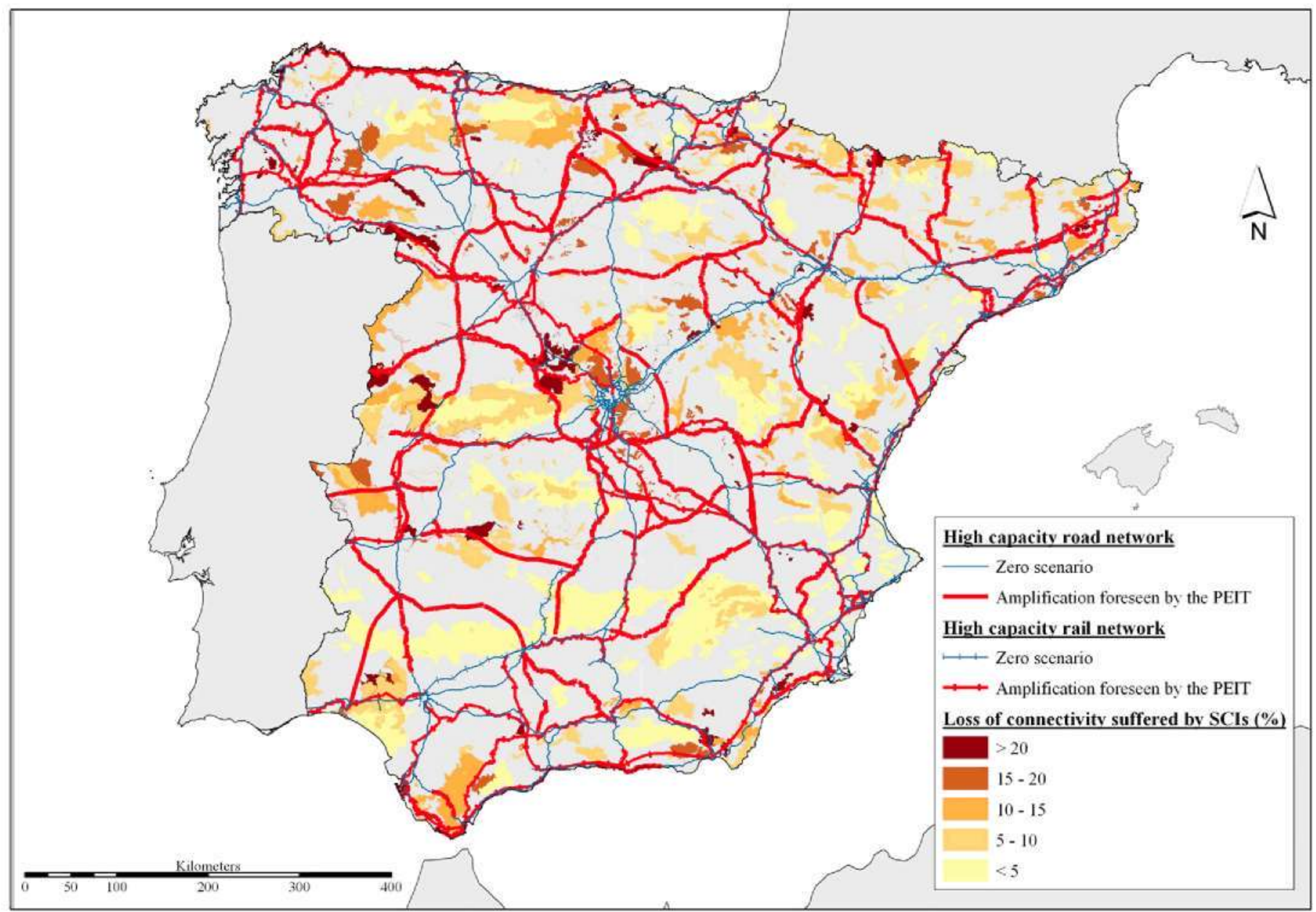

Fig. 6. Loss of connectivity of the SCIs in Spain as a consequence of the PEIT. The darker colours represent greater impact. 


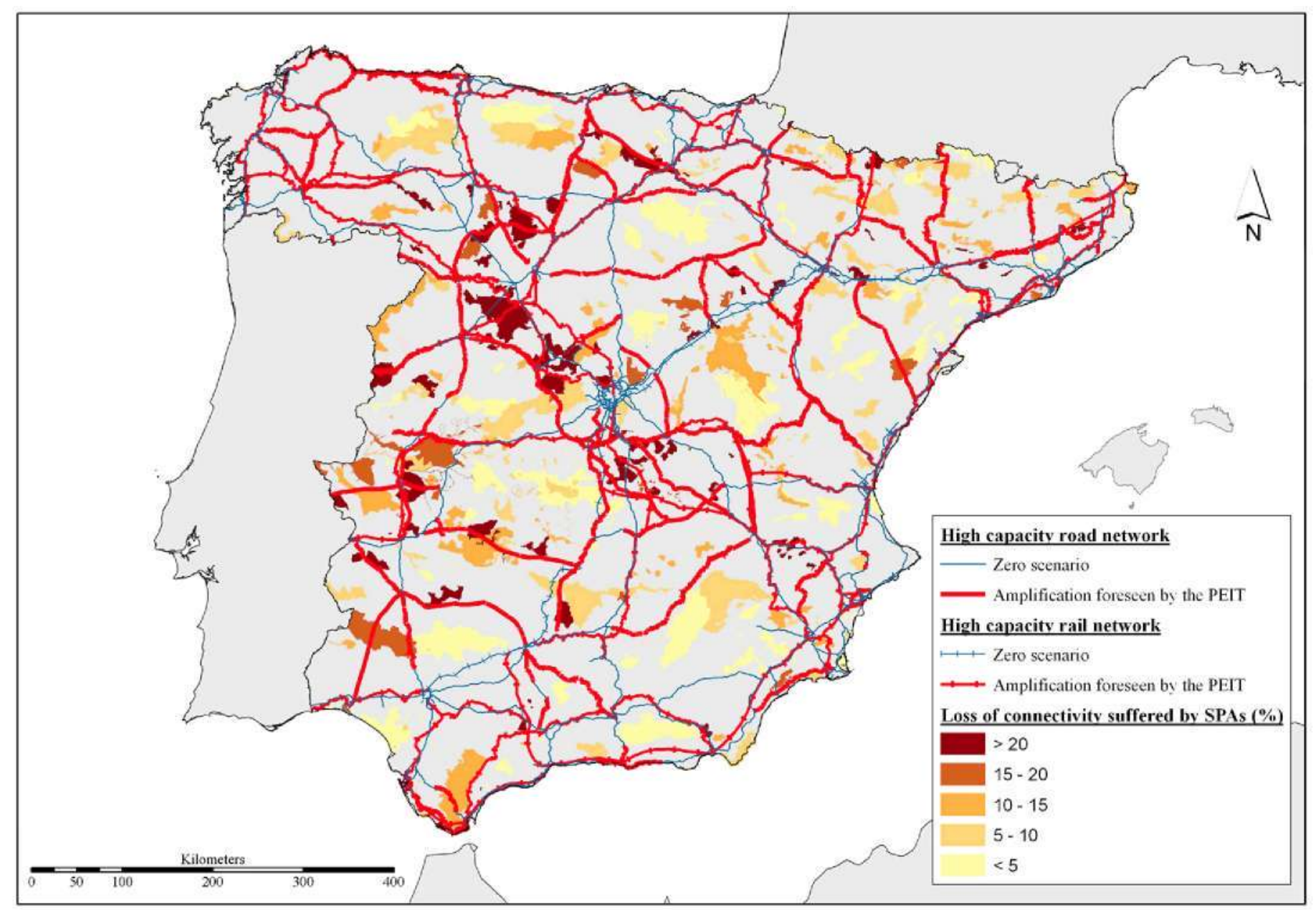

Fig. 7. Loss of connectivity of the SPAs in Spain as a consequence of the PEIT. The darker colours represent greater impact.

1. Aggregation of the starting-point cell map: an aggregate starting-point cell represents the most common type (mode) of habitat among all the starting-point cells available. This simplification means that small patches of other types of habitat intermingled with the aggregated cells are not represented. The origin of the shortest travelling distance is displaced to the centre of each aggregate cell.

2. Aggregation of the destination-cell map: the aggregate destination-cell map provides the aggregate destinations for each type of habitat. The centres of these aggregate cells become the new targets for the minimum travelling distances.

3. Aggregation of the resistance-cell map: a map of aggregate resistance cells is also produced for each type of habitat (at first without taking into account the infrastructures present). The distance an organism travels between its starting point and its destination point is determined by the resistance it faces to this movement (represented by the aggregate resistance cell[s] between those points). The resistance caused by infrastructures is added to the mean resistance value for each aggregate resistance cell, to reflect the final resistance. The reason for this procedure is to avoid a likely loss of information: when two or more lines overlay the same cell, GIS can only use one, chosen randomly.

\subsubsection{Maximum distance}

Habitat type autocorrelation was calculated for the whole territory in four directions. The result was that at $50 \mathrm{~km}$ the probability of finding any habitat type is the same. Hence from this distance, the contribution of the destinations to $\mathrm{Cl}$ is not significant. We chose $50 \mathrm{~km}$ as the maximum distance considered for CI calculation.

\subsubsection{Estimation of the loss of connectivity between scenarios in the case study}

The study area was the whole of peninsular Spain. The $\mathrm{Cl}$ was calculated for two different scenarios. The first, the 'zero scenario' corresponded to the initial situation - that of 2005 , in which the habitats were affected by the road and high-speed rail networks to the extent recognised for that time. The second, or PEIT scenario, involved the superimposition of habitats - those affected by road infrastructures, and those affected by the high-speed rail network as projected for 2020 .

Once the starting, destination and resistance cells of the territory were established, the $\mathrm{CI}$ was calculated (for both scenarios) for each of the starting cells. This provided two raster maps of connectivity in which each starting cell possessed a $\mathrm{CI}$.

The change in $\mathrm{CI}$ was obtained as the difference of the $\mathrm{CI}$ values for each scenario, expressed as a percentage with respect to the initial situation:

Change in $\mathrm{CI}(\%)=\frac{\mathrm{CI}_{\text {PEIT }}-\mathrm{CI}_{\text {zero }}}{\mathrm{CI}_{\text {zero }}} \cdot 100$

Once the loss of connectivity between scenarios for each cell was known, this information was integrated into the SCI and SPA 


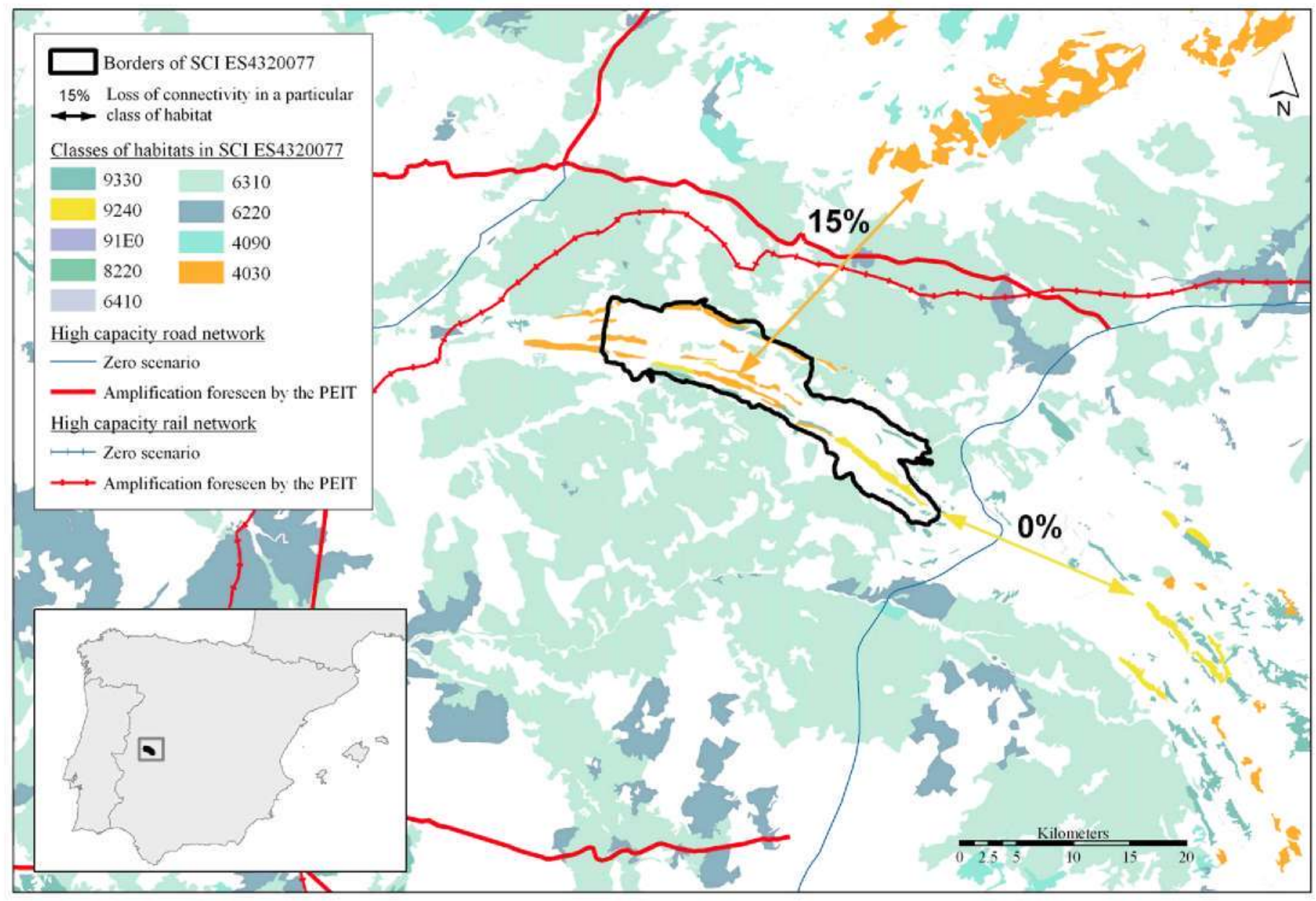

Fig. 8. SCI Monfragüe (EI SCI ES4320077) will suffer a loss of connectivity of some $17 \%$ despite the fact that none of its patches will be crossed by new PEIT infrastructures.

maps. The mean changes in $\mathrm{Cl}$ in these different areas were then calculated to provide summarised information.

\section{Results}

Using this methodology it was possible to calculate the loss of connectivity for all the habitats on the Iberian Peninsula affected by the PEIT. The map of habitats for the extension of the analysed territory covers about 150,000 patches, and the transport infrastructure networks make up more than 30,000 arcs. As the task of processing the information is so complex, the calculation of $\mathrm{CI}$ was programmed in Arc/Info, and the model was simplified to eliminate inherent problems. These simplifications - consisting of optimised aggregations and single resistance maps for each habitat were assumed not to lead to any significant loss of ecological information.

The CIs were calculated for the entire area considered to be habitat in both the zero and PEIT scenarios, thus providing two raster connectivity maps. The difference (expressed as a percentage) between these indicator values reflects the loss of connectivity that Spanish habitats will suffer. Fig. 3 shows this predicted loss of connectivity, with zones suffering greater impact highlighted in darker colours. This connectivity loss map allows the highly impacted areas to be easily identified, e.g. Fig. 3 shows four zones in which the loss of connectivity is especially high due to the infrastructures plan (PEIT). The main reason for the loss of connectivity is that these areas currently do not have a high-speed rail track, and the
PEIT contemplates the construction of a new one. The case of Asturias (zone A, Fig. 3), in the north of Spain beyond the Cantabrian mountain system, shows the traditional isolation of Asturias' railway network from the rest of the Spanish railway system. The construction of two new high-capacity roads between two high-population cities (Oviedo and Gijón), with a corridor running parallel to the coast towards the west, also significantly reduces connectivity. The southern and central part of Galicia (zone B, Fig. 3) will also be hard hit. The large railway corridors in the southeast of the Peninsula (zone C, Fig. 3), joining Madrid with other cities such as Cuenca, Albacete and Alcázar de San Juan, isolate a zone which will suffer great loss of connectivity. Finally, the projected rail corridor between Madrid and Portugal (zone D, Fig. 3), along with the new highcapacity roads to be built in Extremadura (running both north-south and east-west), will lead to very high losses of connectivity.

The loss of connectivity is measured for each cell, allowing aggregations for any target area for which a total value needs to be easily made. For example, in the present case study, Natura 2000 protected areas were selected since they are the European tool for habitat - and hence biodiversity - conservation. The total losses of connectivity, calculated as the area-weighted means of the change in $\mathrm{CI}$, are $9.71 \%$ for the SCIs and $9.63 \%$ for the SPAs (Figs. 4-7).

\section{Discussion and conclusions}

Various authors highlight the importance of studying the functional processes of each species as the only way to accurately 
measure the consequences of the loss of connectivity (Adriaensen et al., 2003). The Hanski approach is based on the variable $\alpha$, which is specific for each species; some authors also study the loss of connectivity through keystone species (Tanner et al., 1994; Tews et al., 2003). However, environmental assessment plans cannot cope with the ecological study of every potentially affected species, and therefore simplified models are required.

One possibility is to calculate the probability of survival using a mean value of $\alpha$, or a range of $\alpha$ values (obtained statistically from a sample of the species present). Another difficulty stems from the interdependence between patches. The number of reproducing individuals, $S$, also depends on the persistence of a certain population in the destination patch. To resolve this, Hanski introduced the term $p_{j}$ (see eq (3), method description section), which is given a value of 0 or 1 depending on the presence of the species in the destination patch. Although the value must be 0 or 1 at any given moment, over an indeterminate time it can be intermediate, as reflected by $p_{i}$ (see eq (2)). Starting with an initial situation determined by the presence or absence of the species in question in each cell, an equilibrium is reached after several iterations. Ecologically, this recreates the effect of 'stepping stones', so that a population is influenced by others that might be very distant. In a direct manner, a patch has a significant influence on others beyond the distance described by $\alpha$, i.e., if the survival probability is calculated without iteration, the effects seen on population dynamics would only be visible at short range; no effects would be seen at longer distances. Since it is impossible to know a priori the number of jterations that a large territory might require until the probability of persistence stabilises, the proposed model was developed to be statistically sensitive to the effects of distance from infrastiuctures.

The $\mathrm{Cl}$ model proposed solves this problem by assuming that all species that share the same habitat also share the same connectivity model; the result is an indicator free of species-specific variables, similar to the one previously proposed by Marulli and Mallarach (2005). It can therefore be used for extensive territories, a common requirement of the environmental assessment of plans and programs. Developed as a computer programme in FragtUls (Mancebo Quintana, 2007) it is fast and easy to use.

In the proposed model, the analysis of connectivity is based on effective distances (Bunn et al., 2000) and allows assessment of the entire set of patches forming the landscape; they are therefore not considered separately. The resistance offered by the landscape matrix and its influence on fragmentation is therefore taken into account. This fact allows us to use this model for infrastructure planning because the main effect - the barrier effect - is measured through this resistance. The inclusion in the model of the effects of the landscape matrix involves establishing layers of resistance a function of the type of habitat, land use and infrastructures present - following the method of Marulli and Mallarach (2005). This simplifies the handling of the resistance values, which is important when analysing large territories. Thus, the model is sensitive to the accuracy of the estimation of such resistance. The model also assumes that movement occurs between patches of the same habitat type; this simplifies matters by not taking into account the movements of species that shift between habitats (eurytopic species).

The method proposed for obtaining the $\mathrm{Cl}$ is a simplification of Hanski's (1994) model for determining the survival capacity of metapopulations. The model requires the establishment of a maximum threshold distance of interaction between patches (beyond which the intermigration of organisms is unlikely). Hanski's model makes it possible to determine this threshold since it reduces the relative weight of all the patches beyond a certain distance. However, in the proposed model, the relative weight of all patches, irrespective of their distance, remains constant. Although there is no way of knowing where the influence of each patch actually ends, this is estimated from the characteristics of the study area, especially the spatial autocorrelation between habitat classes.

By way of functional validation of the proposed indicator, the four questions contemplated by Saura and Pascual-Hortal (2007) are of interest. These questions allowed them to identify four mistakes an indicator should not make: it should not "(i) indicate that landscape connectivity increases with increasing habitat fragmentation; (ii) predict zero connectivity in any landscape containing just one habitat patch, even if that habitat patch covers the whole landscape; (iii) be insensitive to the loss of (possibly large) isolated patches; and (iv) be unable to detect as more important those key stepping-stone patches that, when lost, disconnect the remaining habitat in two or more isolated sets of patches". The proposed Cl commits none of the first three mistakes, though it fails with respect to the fourth. Linear infrastructures cause habitat fragmentation through the loss of habitat and the barrier effect (Geneletti, 2004). The $\mathrm{Cl}$ indicator is sensitive to both effects as, in its formulation, it takes into account not only the area of available patches, but also the barrier imposed to the migration of species (i). The raster methodology used to calculate $\mathrm{Cl}$ considers each habitat cell as a calculi unit; in consequence, even if there is only one patch (ii) or the patch is mainly isolated (iii), Cl is sensitive to its fragmentation. In fact the model's main simplification is the avoidance of reiterated calculation for evaluating the "steppingstone" effect (iv), which makes it viable in large territories. Consequently, the indicator is not sensitive to the disappearance of single stepping-stone patches.

In the present work, the $\mathrm{CI}$ was specifically developed to take into account all parts of the landscape considered habitat, since loss of connectivity was possible even though the infrastructure studied did not directly cross a habitat. For example, the proposed method shows that the connectivity of protected areas in Spain is likely to suffer appreciably from the linear infrastructures projected in the PEIT, even though they may not actually cross the patches making up these areas. For example, Fig. 8 shows how the Monfragüe area will suffer a 17\% loss of connectivity, even though none of its patches are crossed by the proposed infrastructures. Nonetheless, these new roads and railways will lead to the area being surrounded by barriers.

The patches that make up habitats are the ecological units whose connectivity is analysed in order to assess habitat fragmentation. The definition of scenarios allows changes in the $\mathrm{Cl}$ to be calculated. Different statistical aggregations can be performed with respect to the types of protected area or the class of habitat to which patches belong. This avoids one of the most common errors in the analysis of the fragmentation caused by transport infrastructures: the use of artificial boundaries with no ecological basis to define the study area (Geneletti, 2006). The analysis of the study case fails on this point as Portugal and certain French territories were not included, although this was not due to the model, but to a lack of access to geographic information.

The use of the model in the two scenarios outlined in this work made it possible to determine the losses of connectivity likely to be suffered by Spanish habitats due to the PEIT. It might also reflect the reduction in the likelihood of the survival of the species affected, according to Hanski's metapopulation model.

Closer study should be given to the infrastructure projects in which the greatest changes are expected. Sometimes, a lack of detail in planning leads to an inaccurate depiction of the true situation, and erroneous decisions may be taken.

Further studies of this index, such as sensitivity analysis, comparison with field studies, etc. should be carried out in order to ensure a fast and robust transfer of this model to the decisionmaking process. 
The following conclusions can be drawn:

- The connectivity indicator proposed allows the estimation of the connectivity between all the patches of a territory, without imposing any artificial (non-ecologically based) boundaries.

- The analysis of connectivity based on effective distances allows the entire set of patches in a landscape to be analysed.

- The model proposed appears to be a useful tool for the analysis of fragmentation caused by plans for large territories, and on a detailed scale. It should be remembered, however, that it is dependent on an evaluation of the landscape's resistance to the movement of organisms.

- The raster format used allows the $\mathrm{Cl}$ to be determined simply from maps of habitats, infrastructures and land cover.

- The use of the $\mathrm{CI}$ index is suitable for the framework of Strategic Environmental Assessment. It has potential to be used as a tool for Strategic Environmental Assessment screening in the very early stages of decision-making. The results obtained in the present work show it can be useful for evaluating the impact of infrastructures on connectivity in the early decision-making process, even though the territory and quantities of information involved are very large.

- The case study showed that Spanish SCIs and SPAs are very sensitive to the building of new infrastructures.

\section{Acknowledgements}

We would like to thank Emilio Ortega Pêrez for his valuable help updating and fixing the topology of the road and railroad network datasets used in this work. We also thank Mr. Adrian Burton and Mrs. Prudence Brooke-Turner for their translation and revision of the English manuscript.

This research work has been granted by the Spanish Ministerio de Fomento (Ministry of Civil Works) under the project "Análisis del impacto del Plan Estratégico de Infraestructuras y Transporte (PEIT) sobre la biodiversidad en el territorio español".

\section{References}

Adriaensen, F., Chardon, J.P., De Blust, G., 5winnen, E., Villalba, S., Gulink, H., Matthysen, E., 2003. The application of 'least-cost' modelling as a functional landscape model. Landscape and Urban Planning 64, 233-247.

Baskent. E.Z., 1999. Controlling spatial structure of forested landscapes: a landscape study towards landscape management. Landscape Ecology 14, 83-97.

Bunn, A.G., Urban, D.L., Keitt, T.H., 2000. Landscape connectivity: a conservation application of graph theory. Journal of Environmental Management 59, 265-278.

Collinge, S., 1996. Ecological consequences of habitat fragmentation: implications for landscape architecture and planning. Landscape and Urban Planning 36, 59-77.

Dijkstra, E.W., 1959. A note on two problems in connexion with graphs. Numeriske Mathematik 1. 269-271.

Drielsma, M. Manion, G., Ferrier, S., 2006. The spatial links tool: automated mapping of habitat linkages in variegated landscapes. Ecological Modelling 200, 403-411.

Dunning. J.B., Danielson, B.J., Pulliam, H.R., 1992. Ecological processes that affect populations in complex landscapes. Oikos 65, 169-175.

EEA, 2000. Corime land Cover 2000 (CLC2000) $100 \mathrm{~m}$ version $8 / 2005$, Online URL: http://dataservice.eea.europa.eu/dataservice/metadetails.asp?id=822.

European Commission, 2003. CoST Action 341. Habitat Fragmentation Due to Transport lnfrastructure. Directorate-General for Research, Brussels.

Fahrig, L., 2002. Effect of habitat fragmentation on the extinction threshold: a synthesis. Ecological Applications 12, 346-353.

Falurig. L., Merriam, G. 1985. Habitat patcl connectivity and population survival. Ecology 66, 1762-1768.

Forman, R.T., 1995. Land mosaics: the ecology of landscapes and regions. Cambridge University Press, Cambridge, UK.

Forman, R.T.T., Alexander, L.E., 1998. Roads and their major ecological effects. Annual Review of Ecology Evolution and Systematics 29, 207-231.

Geneletti, D., 2004. Using spatial indicators and value functions to assess ecosystem fragmentation caused by linear infrastructures. Applied Earth Observation and Geoinformation 5, 1-15.
Geneletti, D., 2006. Some common shortcomings in the treatment of impacts of linear infrastructures on natural habitat. Environmental Impact Assessment Review 26, 257-267.

Gontier, M., Barfors, B., Mörtberg, U., 2006. Biodiversity in environmental assessment - current practice and tools for prediction. Environmental Impact Assessment Review 26, 268-286.

Gustafson, E.J., Gardner, R.H., 1996. The effect of landscape heterogeneity on the probability of patch colonization. Ecology 77, 94-107.

Hanski, I., 1994. A practical model of metapopulation dynamics. Joumal of Animal Ecology 63, 151-162.

Jaeger, J.A.C., Bertiller, R., Schwick, C., Müller, K., Steinmeier, C., Ewald, K.C. Glazoul, J., 2008. Jmplementing landscape fragmentation as an indicator in the Swiss Monitoring system of sustainable Development (MONET). Joumal of Environmental Management 88, 737-751.

van Langevelde, F., van Dooremalen, C., Jaarsma, C.F., 2009. Traffic mortality and the role of minor roads. Joumal of Environmental Management 90, 660-667.

Lindenmayer, D.B., Franklin. J.F., 2002. Conserving Forest Biodiversity: a Comprehensive Multiscaled Approach. lsland Press, Washington, $351 \mathrm{pp}$.

MacArthur, R.H., Wilson, E.0., 1967. The Theory of lsland Biogeography. Princeton University Press, Princeton, NJ.

Mancebo Quintana, S., 2007. FragtUls. Online URL: http://topografia.montes.upm. es/fragtuls.html.

Marulli. J., Mallarach. J.M., 2005. A Gl5 methodology for assessing ecological connectivity: application to the Barcelona metropolitan area. Landscape and Urban Planning 71, 243-262.

Mata, C., Hervás, I., Herranz, J., Suárez, F., Malo, J.E., 2008. Are motorway wildlife passages worth building? Vertebrate use of road-crossing structures on a Spanish motorway. Joulnal of Environmental Management 88, 407-415.

May, R.M., 1975. Patterns of species abundance and diversity. In: Cody, M.L. Diamond. J.M. (Eds.), Ecology and Evolution of Communities. Harvard University PTess, Cambridge, Massachusetts, USA, pp. 81-120.

McGarigal, K., Marks, B.J., 1995. FRAGSTATS: Spatial Pattern Analysis Program for Quantifying landscape Structure. Gen. Tech. Report PNW-GTR-351. USDA Forest Service, Pacific Northwest Research Station, Portland, OR.

Ministerio de Fomento, 2005. PEIT: Plan Estratégico de Infraestructuras y Transporte 2005-2020. Secretaría General Técnica. Ministerio de Fomento, Madrid.

Ministerio de Medio Ambiente, 1995. Mapa de Hábitats. Online URL: http:/wwww. mma.es/portal/secciones/biodiver'sidad/banco_datos/info_disponiblefindex habitat_descargas.htm.

Moilanen, A. Hanski, 1., 2001. On the usage of connectivity measures in spatial ecology. Oikos 95, 147-151.

Nikolakaki, P., 2004. A GIS site-selection process for habitat creation: estimating connectivity of habitat patches. Landscape and Urban Planning 68, 77-94.

Official Journal of European Communities, 2001. Council Directive 97/11/EC of the European Parliament on the assessment of the effects of certain plans and programs on the environment. Official Journal L 197/30 [21/07] 2001].

Opdam, P., Foppen, R., Vos, C., 2001. Bridging the gap between ecology and spatial planning in landscape ecology. Landscape Ecology 16, 767-779.

Pascual-Hortal, l., Saura, 5., 2006. Comparison and development of new graph based landscape connectivity indices: towards the priorization of habitat patches and corridor's. landscape Ecology 21, 959-967.

Ouine, C.P., Watts, K., 2009. Successful de-fragmentation of woodland by planting in an agricultural landscape? An assessment based on landscape indicators. Journal of Environmental Management $90,251-259$.

Riitters, K.H., O'Neill, R.V., Hunsacker, C.T. Wickham, J.D., Yankee, D.H. Timmins, 5.P., Jones, K.B. Jackson, B.l., 1995. A factor analyses of landscape pattern and structure metrics. landscape Ecology 10, 23-39.

Rutledge, D., 2003. Landscape Indices as Measures of the Effects of Fragmentation: Can Pattern Reflect Process? New Zealand Department of Conservation, New Zealand.

Saunders, D.A., Hobbs, R.J., Margules, C.R., 1991. Biological consequences of ecosystem fragmentation: a review. Conservation Biology 5, 18-32.

Saura, S., Pascual-Hortal, L., 2007. A new habitat availability index to integrate connectivity in landscape conservation planning: comparison with existing indices and application to a case study. landscape and Uban Planning 83, 91-103.

Serrano, M., Sanz, L., Puig, L., Pons, J., 2002. landscape fragmentation caused by the transport network in Navarra (5pain). Two-scale analysis and landscape integration assessment. Landscape and Urban Planning 58, 113-123.

Stevens, M.5. Polus, E., Wesseling. R.A., Schitickzelle, N., Baguette, M., 2004. Quantifying functional connectivity: experimental evidence for patch specific resistance in the natterjack toad (Bufo calamita). Landscape Ecology 19, 829-842.

Subdirección General de Conservación de la Biodiversidad, 2005. Red Natura 2000 Organismo Autónomo de Parques Nacionales, Espańa.

Tanner, J.E., Hughes, T.P., Connell, J.H., 1994. Species coexistence, keystone species, and succession: a sensitivity analysis. Ecology 8, 2204-2219.

Taylor, P.D., Fahrig, 1., Henein, K., Merriam, G., 1993. Connectivity is a vital element of landscape structure. Oikos 68, 571-573.

Tews, l., Brose, U., Grimm, V., Tielbörger, K., Wichmann, M.C., Schwager, M., Jeltsch, F, 2003. Animal species diversity dijven by habitat heterogeneity/diversity: the importance of keystone structures. Journal of Biogeograpliy 31, 79-92.

Tischendorf, l. Fahrig, L, 2000a. How should we measure landscape connectivity? landscape Ecology 15, 633-641.

Tischendorf, L, Fahrig, l, 2000b. On the usage and measurement of landscape connectivity. Oikos $90,7-19$. 